\title{
Rotating Liner Hanger Bearing Frictional Heat Field and Thermal- mechanical Coupling Simulation
}

\author{
Haiqiang Sun ${ }^{1, a^{*}}$ \\ ${ }^{1}$ China university of geosciences Beijing, 100083 \\ ${ }^{a}$ E-mail: shqcugb@126.com
}

\begin{abstract}
Keywords: frictional heat field; thermal stress; thermal deformation.
Abstract. Based on the bearing frictional theory and thermal theory, establishing a three-dimensional finite element model of the rotating liner hanger bearing, using finite element software ANSYSWorkbench to simulate the temperature field distribution. Discussing the influence of the slurry temperature and the frictional heat on the rotating liner hanger bearing temperature field, the thermal stress and the thermal deformation, Analysis results show that the existence of the temperature field has a significant influence on the contact stress, and has a certain influence on deformation of the bearing components as well.
\end{abstract}

\section{Introduction}

Rotating liner hanger receives a high attention at cementing site because of its good cementing effect in ultra-deep wells, horizontal wells and angle high angle wells ${ }^{[1]}$. The rotating liner hanger was developed in 1920s. Bearing is the key part of the rotating liner hanger ${ }^{[2]}$. When the bearing works, not only bear the high load from outside, but also run at high temperature and slurry environment at the downhole $^{[3]}$. At the same time, frictional heat which produced by the large frictional torque on rotating liner hanger bearing makes the bearing roller surface wear intensively and then reduce the bearing life.

The study of this bearing is rare. Sliding bearing was used before the thrust roller bearing was developed. Lanrong Ma developed a kind of special bearings for the rotating liner hanger, but the bearing life can't meet the practical need. Jianchong Wang simulated the slurry environment at the downhole . but he didn't consider the friction heat ${ }^{[4]}$. In addition, Yu Wang studied this kind of bearing sealing problem, Zhijun Niu studied the roller shape modification.

Based on the theory of bearing frictional and thermology theory, this paper discuss the impact of high-temperature slurry and the friction heat on temperature field distribution, thermal stress and the thermal deformation.

\section{The thermal analysis model of rotating liner hanger bearing}

The heat transfer process. Rotating liner hanger bearing has two heat sources, one is the high temperature slurry from outside of the bearing, this part of the heat through the heat conduction effects the bearing, then each part of bearing transfers heat through the heat conduction. The other part is the rotating liner hanger bearing produced friction heat on the process of rotating, this part of heat is produced mainly in the contact area. Because the simulation of the frictional heat takes a lot of computer resources, it is impossible to simulate the rolling calorific value which is produced in the whole rotary process of the rotating liner hanger bearing. This paper calculates the single roller heating power based on the bearing frictional thermology theory firstly, and then assigns the heat to the raceway (the seat ring and the shaft ring) and the roller according to the proportion of 1:1.

The calculation of friction heat. The calorific value of the rotating liner hanger produced by the frictional torque ${ }^{[5]}$.The frictional torque depends on bearing structural parameters, load, speed, lubricant, etc ${ }^{[6]}$. Frictional torque can be divided into torque related to structural parameters torque and 
torque related to external load. Therefore, the rotating liner hanger frictional torque can be written asError! Bookmark not defined.:

$$
M=M_{0}+M_{1}
$$

(1)

Calculate $M_{0} \cdot M_{0}$ related to bearing types, lubricant viscosity and quantity and the bearing speed.

$$
\begin{aligned}
& v n \geq 2000 \\
& M_{0}=10^{-7} f_{0}(v n)^{\frac{2}{3}} D_{m}{ }^{3} \\
& v n \leq 2000 \\
& M_{0}=160 \times 10^{-7} f_{0} D_{m}{ }^{3}
\end{aligned}
$$

(2)

$D_{m}$--- The average diameter of the bearing. $m m .0 .5(D+d)$

$f_{0}$---Coefficient related to the types of bearings and lubrication.

$n$---Bearing speed. $r / \min$

$v$---The lubricant viscosity under bearing operating temperature. $\mathrm{mm}^{2} / \mathrm{s}$

Calculate $M_{1} \cdot M_{1}$ mainly related to elastic hysteresis and contact surface differential sliding friction loss.

(3)

$$
M_{1}=f_{1} P_{1} D_{m}
$$

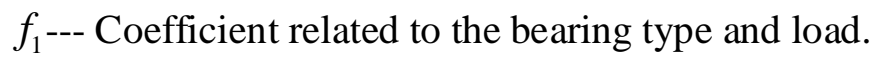

$P_{1}$--- The bearing load when calculate the bearing friction torque. $N$

Calculate the friction power. The friction power ${ }^{[7]}$ :

$$
H_{f}=1.047 \times 10^{-4} n M
$$

(4)

$n$---Bearing rotating speed. $r / \mathrm{min}$

$M$---Bearing friction torque. $N \cdot \mathrm{mm}$

Heat transfer between bearing components. For the rotating liner hanger bearing system, there are three types of heat transfer forms: one is heat transfer between the bearing components; the second one is the heat convection between bearing assemblies and the air in the bearing chamber; the third one is the thermal radiation. Among the three transfer forms, the second one and the third one have little impact on the distribution of the bearing temperature field, Therefore, this chapter only discuss the effect of the heat conduction on the bearing temperature field. Heat transfer occurs between the bearing components .The equation is ${ }^{[8]}$

$$
H_{c}=\frac{k S}{l}\left(T_{1}-T_{2}\right)
$$


$k$--- Coefficient of thermal conductivity. $\mathrm{W}\left(m \cdot{ }^{\circ} \mathrm{C}\right)$

$l$--- Distance between two points. $m$

$T$---Temperature at two points. ${ }^{\circ} \mathrm{C}$

$S$---The area of the vertical direction of heat flow between two points. $\mathrm{m}^{2}$

\section{Rotating liner hanger bearing temperature field simulation}

finite element model. The rotating liner hanger bearing finite element model is established by threedimensional entity element which is called solid164, the materials is ZGCr15, the elastic modulus is $209 \mathrm{GPa}$ and the poisson ratio is 0.3 , the coefficient of thermal conductivity is $44 \mathrm{~W} / \mathrm{m} \cdot{ }^{\circ} \mathrm{C}$. The seat ring and the shaft ring are meshed by mapping grid. In contact area, there is a grid subdivision. The roller adopt free meshing, the grid size is $1 \mathrm{~mm}$. The retaining ring adopt free meshing too and the grid size of $2 \mathrm{~mm}$.

Steady state thermal should be calculated first, and then import the result to static analysis module. The thermal power of a single roller and raceway contact area is $23.7 \mathrm{~W}$ which is calculated by the formula $1 \sim 3$. Retaining ring surface applied load a temperature of $150{ }^{\circ} \mathrm{C}$ (slurry temperature). Impose concentrated force $47620 \mathrm{~N}$ on upper surface of the shaft ring (equivalent to bearing overall carrying $100 \mathrm{t}$ ).

The simulation results.

The temperature field result analysis. Figure 1 shows under the effect of high temperature slurry, the rotating liner hanger bearing temperature field distribution. Figure 2 shows under the comprehensive function of high-temperature slurry and friction heat, the bearing temperature field distribution.

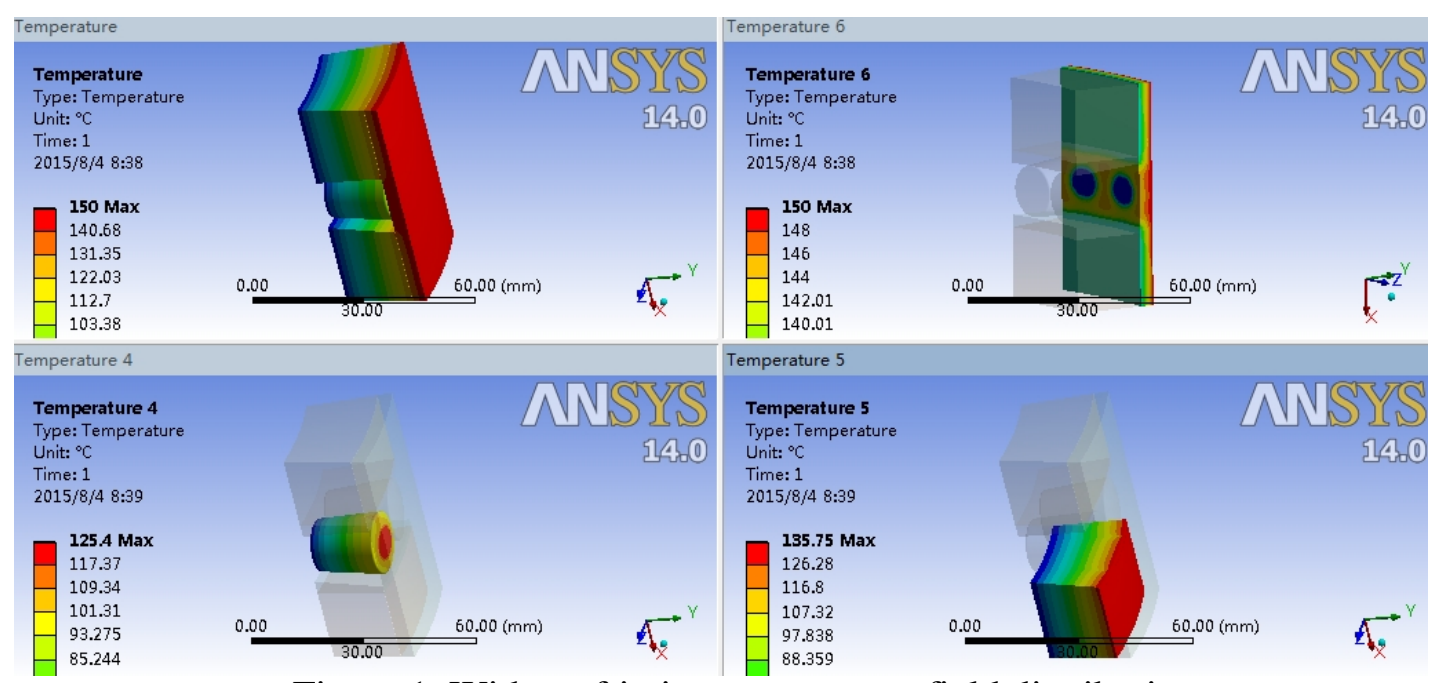

Figure 1. Without friction temperature field distribution 


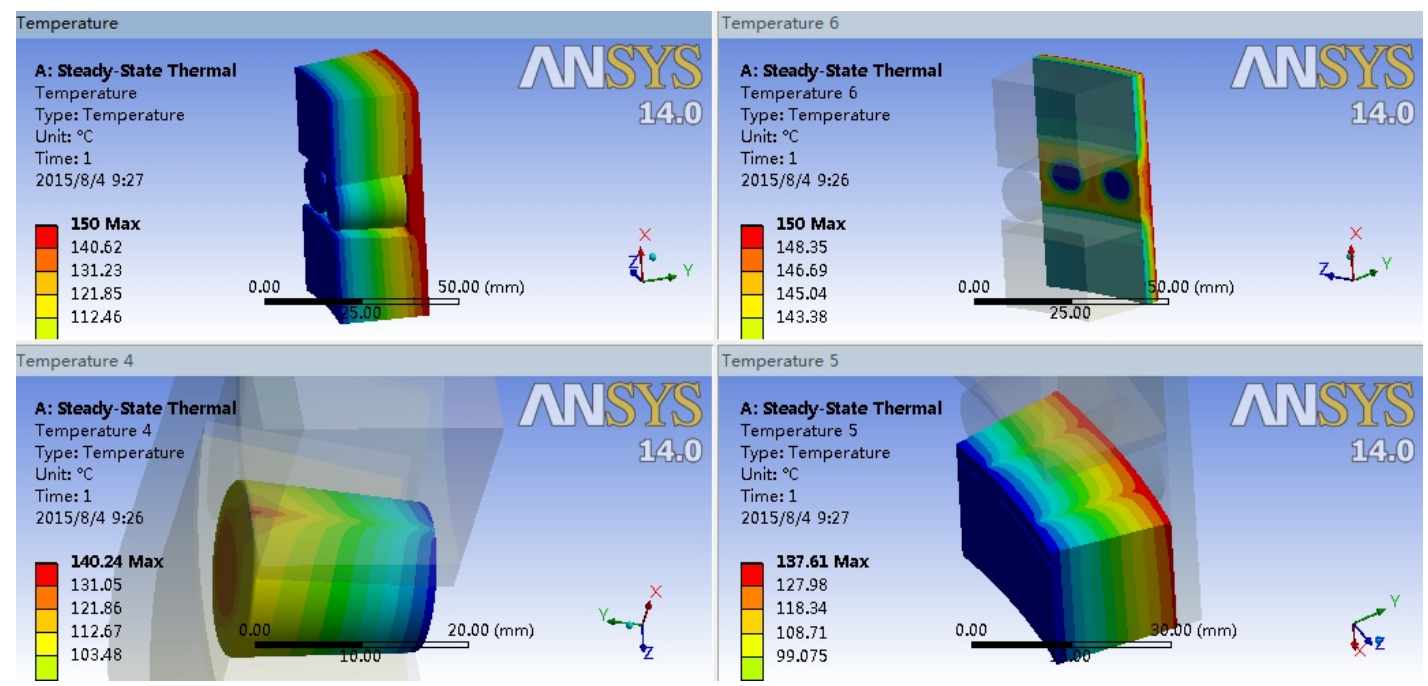

Figure2. Join friction temperature field distribution

From figure 1 and figure 2 , it can be seen that friction power works on the roller and raceway contact area influence the temperature distribution. Along the roller's axial, take a series of points on roller contact surface area. Check the temperatures and then drawing as figure 3.

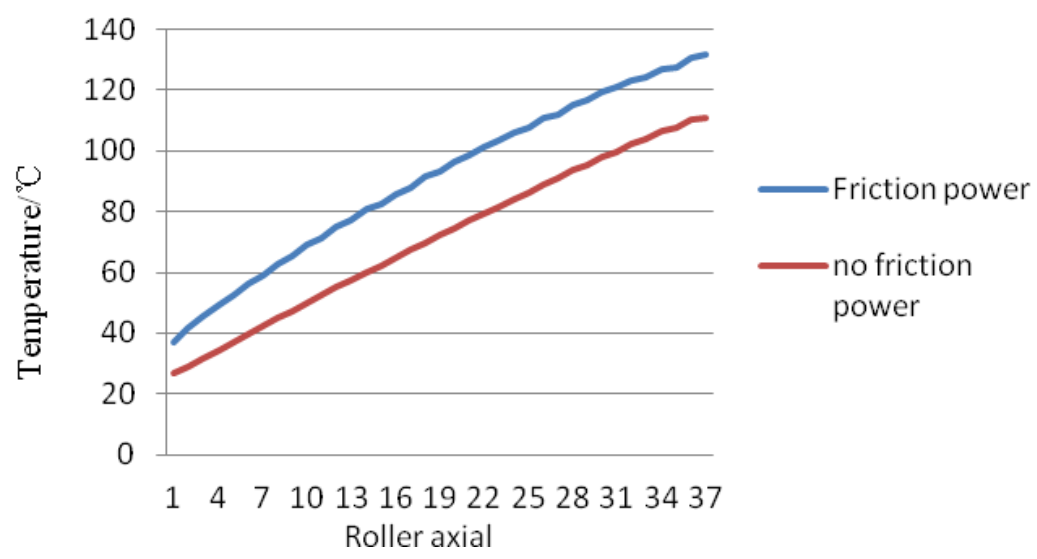

Figure3. Friction impact on roller contact region's temperature

By figure 3, it can be seen that the trends of the two curve are same, the temperature from the smaller side of the roller to the larger side rise gradually. The highest temperature of the roller with friction power is $131.94{ }^{\circ} \mathrm{C}$, the highest temperature of the roller with no friction power is $110.63{ }^{\circ} \mathrm{C}$, the existence of the friction power makes the temperature of the roller contact region rise, The maximum difference temperature value is $21.31{ }^{\circ} \mathrm{C}$, the maximum temperature had occurred in roller large end, and the friction power makes the distribution of the roller temperature no longer uniform. As a result, We can draw a conclusion that the frictional power can't be neglected.

The contact thermal stress and deformation analysis. Figure 4 shows the rotating liner hanger bearings simulation results under the action of static load, including total equivalent stress, contact stress, total deformation and deformation of the roller. The same as figure 5 but under the action of static load and slurry and frictional thermal load. The results show that in the case of static load the maximum contact stress reach to $2368.8 \mathrm{MPa}$, however, in the case of thermal-mechanical coupling, the maximum contact stress increase to $2449.3 \mathrm{MPa}$. This is due to the material performance parameter that related to the thermal, at the same time, the case of thermal-mechanical coupling can also increase the maximum contact stress. The roller total deformation under static load is $0.0522 \mathrm{~mm}$, however, in the case of thermal-mechanical coupling, it reach to $0.0533 \mathrm{~mm}$. The results show the thermal can 
make the bearing components deformation increases, which could provide a reference for the design of the bearing initial clearance.

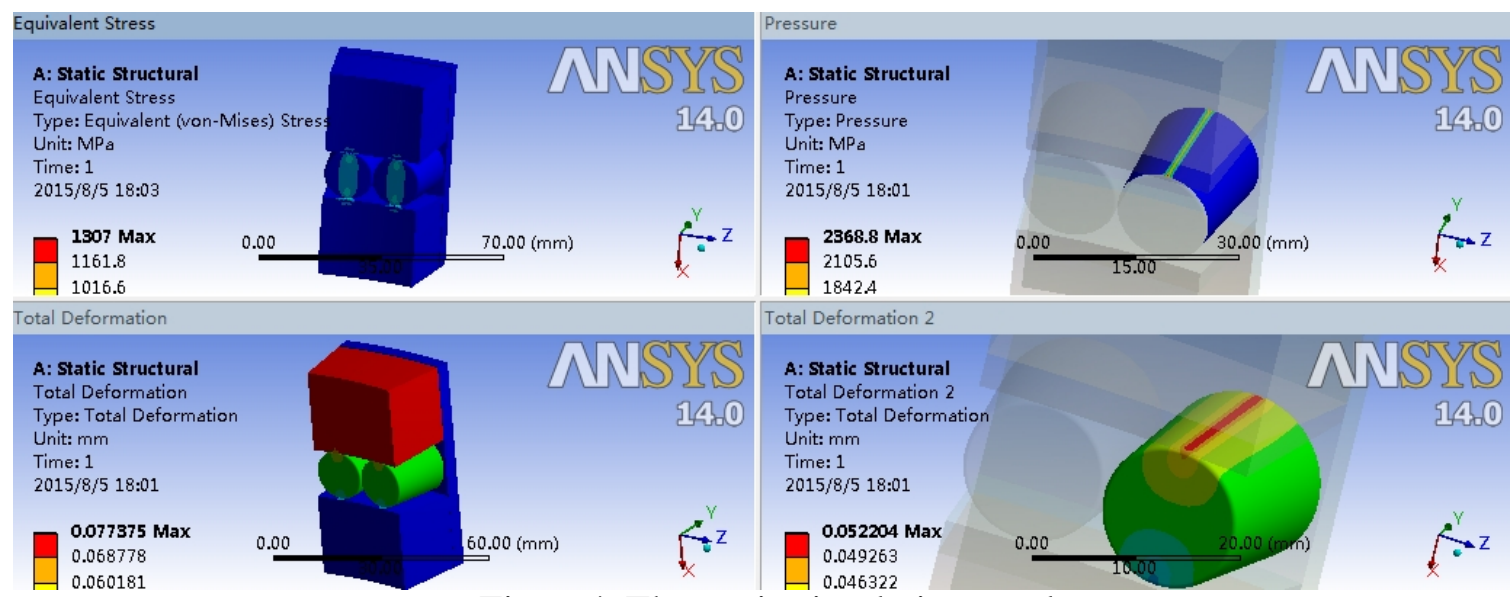

Figure4. The static simulation results

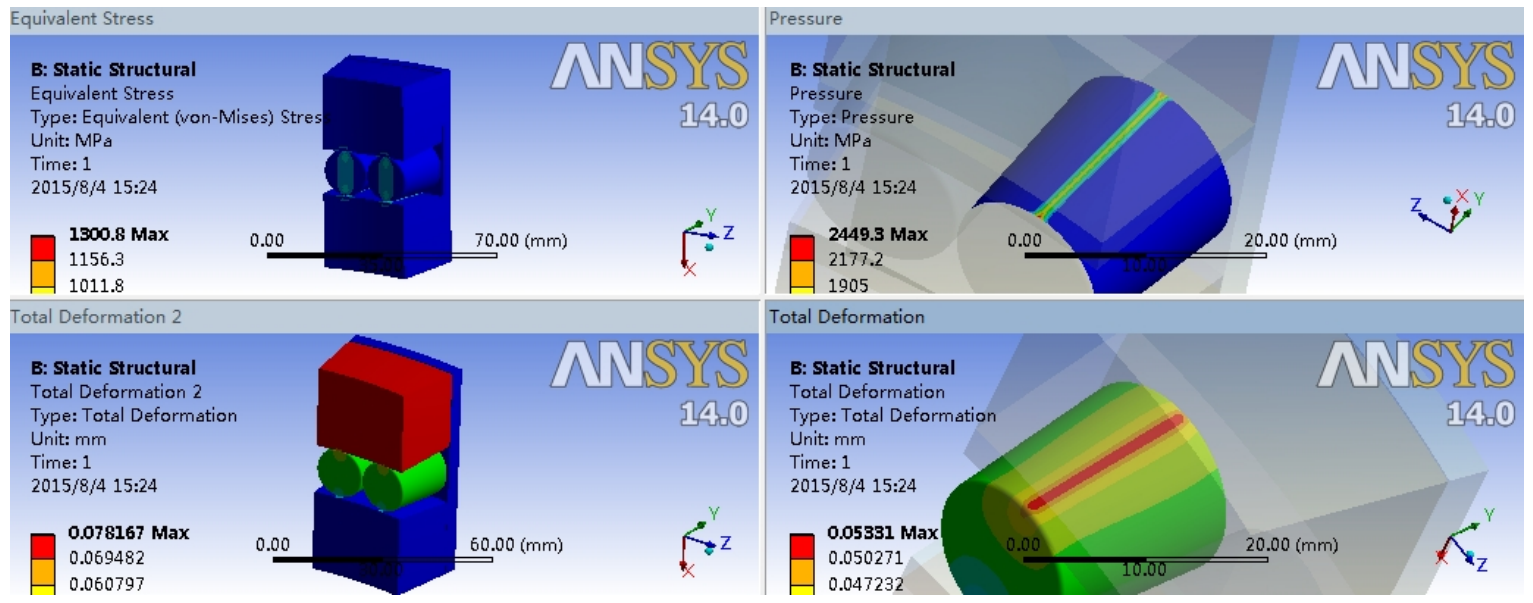

Figure5. Thermal-mechanical coupling simulation results

\section{Summary}

Based on the theory of bearing tribological and thermal theory,this paper discuss the impact of frictional heat and high temperature slurry on the bearing temperature field distribution and discuss the influence of above factors on rotating liner hanger bearing contact stress and deformation. The conclusions are as follows:

The frictional heat generated by frictional torque of rotating liner hanger bearing can't be ignored for the temperature field distribution.

The existence of the thermal load of rotating liner hanger has significant effects on the maximum contact stress of the bearing.

Thermal load can increase the bearing components deformation, which can provide a reference for the initial clearance of bearing design.

\section{References}

${ }^{[1]}$ ZHANG Hong-wei, RUAN Chen-liang, LI Peng-fei, Rotary Liner Cementing Tool in the Application of Ultra-deep Horizontal Wells, Oil field equipment.41(2012)68 71. 
${ }^{[2]}$ ZHANG Qing-yu,ZHANG SHAO-xian,ZHENG DIAN-fu, Rotating liner cementing technology status quo ,Drilling\&production technology. 30(2007), 35 37..

${ }^{[3]}$ MA LAN-rong, GUO CHAO-hui,YANG DE-kai, Key Technology Study and Performance Test of Rotating Liner Cementing, Oil field equipment. 38(2009)67 70.

${ }^{[4]}$ WANG JIAN-chong, Finite Element Analysis of Rotary Liner Hanger Bearing in Ultra-Deep Well Drilling Based on ANSYS WORKBENCH, May 2014.

${ }^{[5]}$ QIN DA-tong,XIE LI-yang, Modern mechanical design manual,2(2011) 281 285.

${ }^{[6]}$ T.A.Harris,M.N.Kotzalas, Advanced Concepts of Bearing Technology, September 2009.

${ }^{[7]}$ LI YI-geng, Thermal-Mechanical Coupling Analysis of Coated Cylindrical Roller Bearing, December,2011.

${ }^{[8]}$ XU JIAN-ning, QU WEN-tao,ZHAO-ning, Analysis of Thermal Deformation and Temperature Field for Plain Thrust Bearing, Lubrication engineering.8(2006),120 123. 